\title{
'Science is Measurement'; ABMAP, a Database of Domestic Animal Bone Measurements
}

\author{
Dale Serjeantson
}

\begin{abstract}
A database of animal bone measurements, the Animal Bone Metrical Archive Project (ABMAP), is now available on the Web at http://ads.ahds.ac.uk/catalogue/specColl/abmap. The measurements can be downloaded and imported into a spreadsheet. They are of bones of domestic animals from the Neolithic to the 19th century AD from assemblages in England, most from southern England. An example is given of the retrieval of measurements of cattle metacarpals and their application in a scatter diagram. The database is a resource for zooarchaeologists and others concerned with research into prehistoric and early historic domestic livestock and animal husbandry.
\end{abstract}

Keywords: Zoonrchaeology, Bone measurements, Southern Britain, Prehistoric, Historic

\section{Introduction}

In the middle of the nineteenth century, the physicist Lord Kelvin asserted that metrical analysis was the foundation of all scientific study. Kelvin's dictum 'Science is measurement' was even used as the subject of a painting done in 1878 by Henry Stacy Marks. It depicts a scientist holding a tape measure with which he is about to measure a mounted skeleton of what appears to be a heron or other large wading bird (Fig. 1). In zooarchaeology, metrical analysis has been, and continues to be, the basis for many important aspects of the study of animal remains from the past. Measurements are taken to establish the identification of species which are closely related morphologically, the distinctions between wild and domestic forms, the changes over time in the size and shape of the domestic animals, the ratio between the sexes present and the age at death. The 'selection', whether conscious or unconscious, for size and shape in domestic animals is worthy of study as a cultural as well as a biological phenomenon.

Over the years zooarchaeologists worldwide have accumulated millions of measurements of domestic and wild animals. Ideally, these basic scientific data are published with the report on the assemblage, but in practice editors, with a few honourable exceptions (e.g. Fulford and Timby 2000), have been reluctant to publish raw metrical data on animal bones. Most measurements taken since the mid 1980s have been recorded in computer files and the existence of the Web now allows these data to be readily shared with other workers. The database described here is a pioneering attempt to make a body of bone measurements available to all.

The Animal Bone Metrical Archive Project (ABMAP) collects together metrical data on the main domestic animals from assemblages recorded at the University of Southampton, together with the data from some other sources, in particular the Museum of London Archaeology Service (MoLAS). Though the data are from England, the database is relevant for a wider geographical area. It is now stored in a neutral archival format and is freely available for teaching, learning and research. It can be accessed on the Web at http://ads.ahds.ac.uk/catalogue/ specColl/abmap. The data come in the form of a spreadsheet which can quickly be downloaded and imported as a spreadsheet file. This note describes the contents and gives an example of how the data can be retrieved and used. 


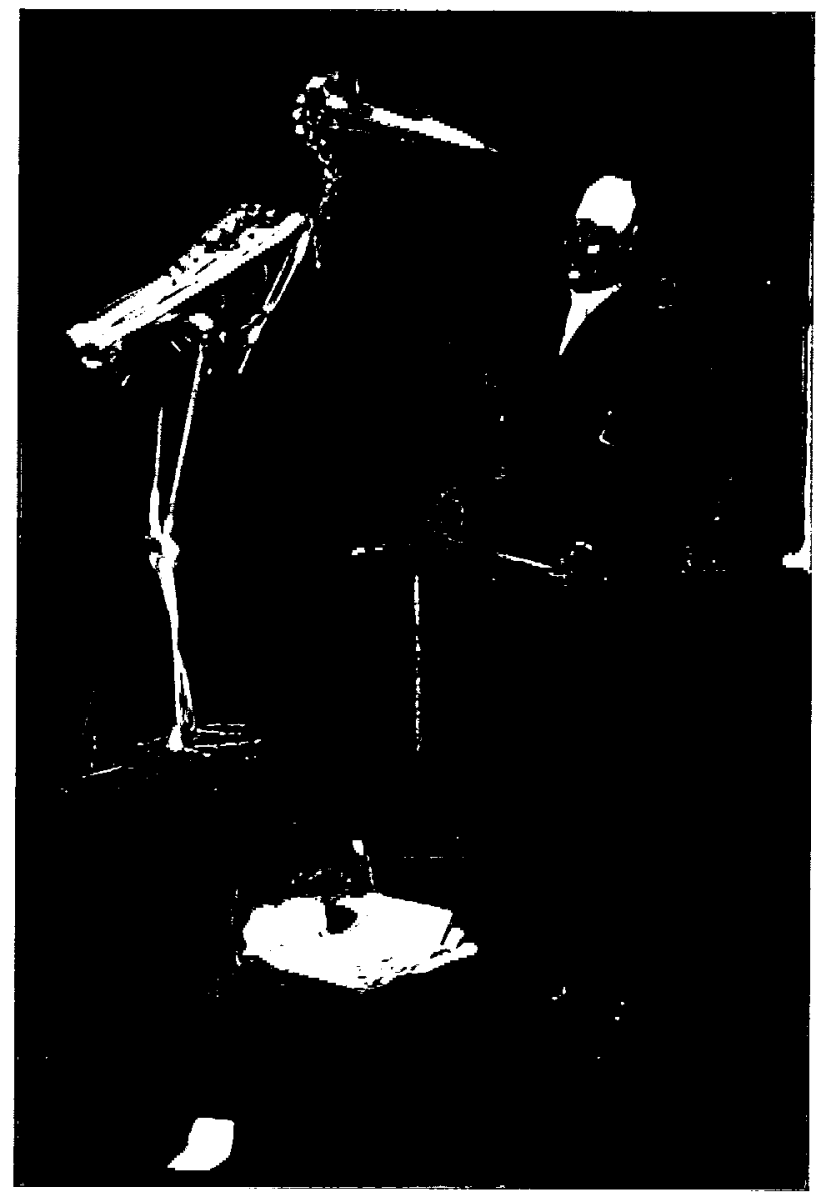

Figure 1. 'Science is Measurement' 1878. Henry Stacy Marks (wwww.artrenewal.org/images/artists/m/marks_ henry_stacy/large/Science_is_Measurement.jpg).

\section{History of the Project}

In the 1990s English Heritage funded a project at the University of Southampton to collect and synthesize metrical data recorded over the past 20 years. The main aim was to assemble the data and ensure that it was kept in a format in which it would be maintained and made accessible. The analysis of the animal bone assemblages from which these measurements derive had been carried out mainly by zooarchaeologists funded through the Ancient Monuments Laboratory, English Heritage, a publicly funded institution, and it seemed appropriate that the resource should be available to others.

The Department of Archaeology at the University of Southampton was one of the institutions which pioneered the recording of animal bones on computer. The Faunal Remains Unit (FRU), funded by the Department of the Environment, now English Heritage, was set up at Southampton in 1975 to record the tons of animal bones which were being excavated on sites in the south of England at the time, many in advance of redevelopment of towns and the building of the M3, the motorway from London to Southampton. More than two hundred assemblages have been recorded at Southampton since 1975, and in the course of this thousands of measurements taken. This huge body of data accumulated at Southampton and in other centres had been recorded on computer since the early 1980s. Since that time the technology has changed, and old records are difficult for researchers and specialists to use. The computer technology of the 1990s allowed the data to be collected together, and the developments in the Web and the setting up of the Archaeology Data Service (ADS) at York since that time now allow the data to be made accessible to all.

\section{The Database}

The project aimed to collect measurements of the main domestic animals, as these are the species most often found on archaeological sites in England. The database includes approximately 25,000 bones of the common domestic animals (Table 1). Most are of cattle and sheep; pig, horse, dog, goat, domestic fowl and goose are also included. The data set is organized by species, anatomical element, period and type of site.

\section{Measurements}

The measurements were originally recorded by many different workers, but all had followed the illustrations and definitions in A Guide to the Measurement of Animal Bones from Archaeological Sites (van den Driesch 1976) and reproduced by Jones et al. (1978). Additional measurements include those on the condyles of sheep and goat metapodia (Payne 1969), on cattle metapodia (Davis 1992), and pig bones and teeth (Payne and Bull 1988). The basic record in ABMAP is the single measurement, but each bone has a unique number which allows measurements from that bone to be associated. Users of the database can choose to download a single measurement, more than one, or all measurements on a selected bone.

\section{Species and bones}

Table 1 shows the species, the number of bones, and the number of measurements. Sheep (including sheep/goat) provide nearly 10,000 bones, and cattle nearly 9000; other species contribute fewer than 1000 measurements each. The mean number of measurements for all elements together is 2.5 per bone, a figure which, surprisingly, does not vary much between species. It might be expected that the species least likely to have been butchered, horses 


\begin{tabular}{lrrr}
\hline Species & Bones (n) & Measurements $(\mathbf{n})$ & Measurements/bone \\
\hline Sheep/goat & 3931 & 8841 & 2.2 \\
Sheep & 5717 & 14871 & 2.6 \\
Goat & 306 & 675 & 2.2 \\
Cattle & 8806 & 22247 & 2.5 \\
Aurochs & 1 & 3 & 3.0 \\
Pig & 2251 & 4194 & 1.9 \\
Horse & 941 & 2471 & 2.6 \\
Dog & 626 & 1655 & 2.6 \\
Domestic fowl & 1725 & 4770 & 2.8 \\
Goose & 427 & 897 & 2.1 \\
\hline Total & 24731 & 60624 & 2.5 \\
\hline
\end{tabular}

Table 1. Species, number of bones, number of measurements, and mean number of measurements per bone.

and dogs, would have more measurements per bone than the main food animals, but they in fact have fewer than domestic fowl and the same number as sheep. The fewest measurements per bone are from pigs, no doubt a reflection of the fact that fewer pigs than other species survived to the age at which the articulations fuse to the bone shaft and are capable of being measured.

\section{Sites and geographical range}

The measurements in ABMAP have been brought together from rather over 100 assemblages, of which most are from sites in the south of England (Table 2). The geographical scope is restricted because the great majority of the archive derives from the FRU and from assemblages from London. It is worth noting however that those counties in south-west England collectively known as Wessex: Hampshire, Dorset, and Wiltshire, together with London, do in fact provide many of the largest and best preserved assemblages in Britain. In these areas of southern central Britain bone preservation can often be particularly good on both rural and urban sites, and in the prehistoric as well as the historic period. The area includes cities such as London, Southampton, Winchester, and Reading which have deep sediments which preserve bone well and where much excavation has been carried out. Where an assemblage has been published, the reference is included in the database.

\section{Temporal scope}

The measurements are from assemblages from all periods from the Neolithic to the nineteenth century AD (Fig. 2). The database includes fields for period and also for the date and/or the date range, as this allows a finer breakdown of the broader periods.

\begin{tabular}{lr}
\hline County & Total \\
\hline Berkshire & 6 \\
Bristol \& Avon & 1 \\
Buckinghamshire & 2 \\
Cornwall & 1 \\
Dorset & 10 \\
Gloucestershire & 2 \\
Hampshire & 33 \\
Hereford \& Worcester & 3 \\
London & 30 \\
Northamptonshire & 1 \\
Oxfordshire & 1 \\
Somerset & 2 \\
Surrey & 3 \\
West Sussex & 1 \\
Wiltshire & 7 \\
\hline Total & 103 \\
\hline
\end{tabular}

Table 2. English counties with assemblages and number of sites per county.

There are many Iron Age and Roman records, but the largest contributions are from the Early Medieval (Anglo-Saxon, Middle Saxon, Late Saxon) and Medieval periods. This bias towards sites dating from $A D$ 700 onwards is largely the result of the concentration of research in this period in Southampton (Bourdillon and Andrews 1997), Winchester (Bourdillon in press; Coy in press) and London (Rackham 1994). A good sample is also included from the 16 th -18 th centuries $A D$, mainly thanks to the many samples from London. These Post-Medieval records are useful especially for those carrying out research into the period of colonial expansion in the New World and the origins of the imported domestic livestock. 


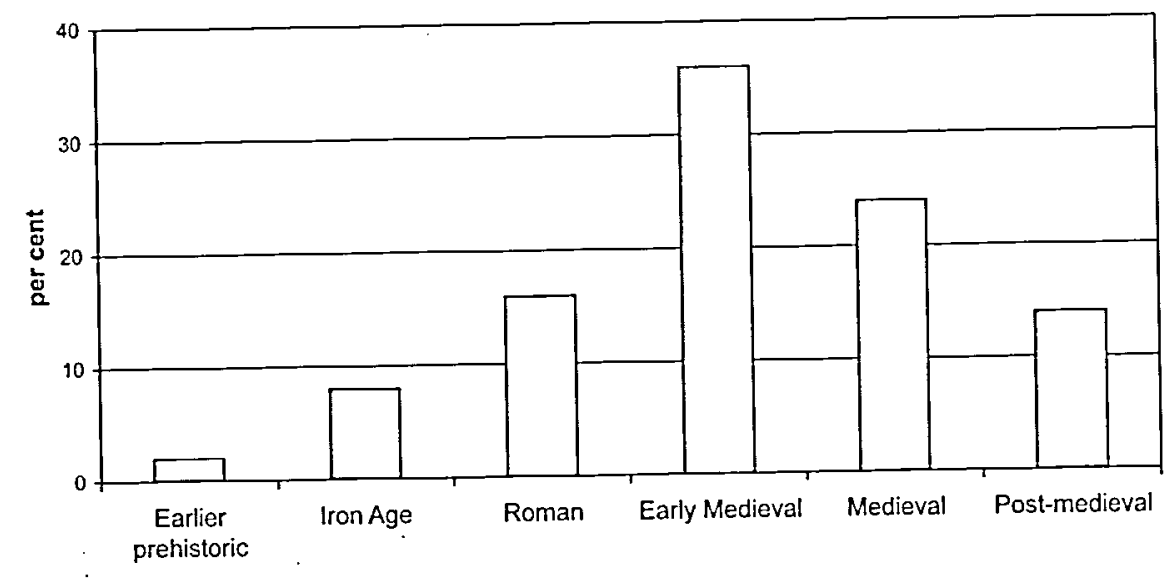

Figure 2. Distribution of measurements by period. The database contains approximately 60,000 measurements.

\begin{tabular}{|c|c|c|c|c|c|c|c|}
\hline & $\begin{array}{r}\text { Neolithic and } \\
\text { Bronze Age } \\
\end{array}$ & Iron Age & Romano-British & Early Medieval & Medieval & Post-medieval & Total \\
\hline Horn core & 1 & 36 & 26 & 122 & 111 & 8 & 304 \\
\hline Mandible & 4 & 23 & 81 & 35 & 11 & & 154 \\
\hline Scapula & 18 & 80 & 152 & 155 & 82 & 31 & 518 \\
\hline Humerus & 15 & 61 & 75 & 141 & 79 & 39 & 410 \\
\hline Radius & 13 & 86 & 115 & 229 & 59 & 25 & 527 \\
\hline Metacarpal & 24 & 74 & 210 & 300 & 270 & 75 & 953 \\
\hline Pelvis & & 8 & & 118 & 58 & 17 & 201 \\
\hline Femur & 2 & 9 & 34 & 94 & 10 & 12 & 161 \\
\hline Tibia & 8 & 80 & 147 & 256 & 211 & 49 & 751 \\
\hline Astragalus & 9 & 90 & 174 & 332 & 247 & 62 & 914 \\
\hline Calcaneum & 2 & 16 & 24 & 109 & 39 & 20 & 210 \\
\hline Metatarsal & 16 & 46 & 175 & 204 & 240 & 92 & 773 \\
\hline Total & 112 & 609 & 1213 & 2095 & 1417 & 430 & 5876 \\
\hline
\end{tabular}

Table 3. Distribution by period of cattle bones with measurements.

\section{Most frequent measurements}

One of the original aims of the project was to contribute to the effective production of animal bone reports by identifying those measurements which are most often taken, and to relate these to the measurements which are most useful for analysis. The database has revealed which bones are most frequently measured, and which least frequently; Table 3 shows these data for cattle. The metacarpal has contributed the greatest number of measurements, presumably because the articulations are often complete enough to measure and because several measurements may be taken on the distal condyles. The metatarsal is the third most frequent bone, with the astragalus second. Metapodial measurements are useful because they can show the stature, the shape and the sex ratio. The next most frequent, and next most useful, are the major limb bones other than the femur, which has few measurements. However, some measurements are infrequent because the bone does not survive well but may be of value in interpreting animal management in the past. For instance, the pelvis may give measurements which discriminate between males and females, but this bone does not yield as many measurements as the main limb bones (Table 3). 


\section{Error checks}

The data were checked for obvious errors (Clark 1999). Various types of errors are liable to appear in any collection of metrical data. There may well be discrepancies between different workers, which result from differential interpretation of the landmark on the bone where the calipers are held, or from different levels of precision. The records will be within the expected range, and cannot be detected. It was possible however to identify certain anomalous results which fall significantly outside the expected size range. Three main types of error emerged:

1. Measurements in the wrong field, for instance a length measurement entered in a field for breath measurement. When this was obvious and unambiguous, the error was corrected.

2. Factor errors. Where it was clear that a decimal point was in the wrong place, the record was corrected.

3. Range errors. Some errors appear to result from the transposition of numbers, e.g. in an expected range of 23 to $30 \mathrm{~mm}$ a measurement was entered as 52 instead of 25 . When unambiguous, these errors were corrected. Errors of these three types were encouragingly rare, fewer than one percent of all records.

\section{Example of the Use of Data from} ABMAP

One example is shown here of the retrieval and use of the measurements from the database. Two measurements of metacarpals from cattle of the Early Medieval period were downloaded and used to produce a scatter diagram, which allows us to investigate the size and shape of cattle in England between the seventh and tenth century $A D$.

The data were retrieved by clicking Query on the Introduction page, and then making the appropriate selections from the Query page (Fig. 3). 'Cattle' was selected in the 'Species' field, 'Metacarpal' in the 'Element' field, and 'Early Medieval' in the 'Period' field. 'GL' and ' $\mathrm{Bd}^{\prime}$ ' were entered in the field for 'Measurement type(s)', and start and end-dates of AD 600 and 1000 were entered in the 'Between' fields. The 'Submit query' box was clicked. When the menu 'Fields to Display' was offered 'Measurement type' and, for this example, 'Site Name' were selected. Altogether 470 records were found which meet the criteria, 132 for GL and 338 for Bd. They are from the Six Dials site in Southampton (part of Hamwic), the Westminster, Maiden Lane and National Gallery sites

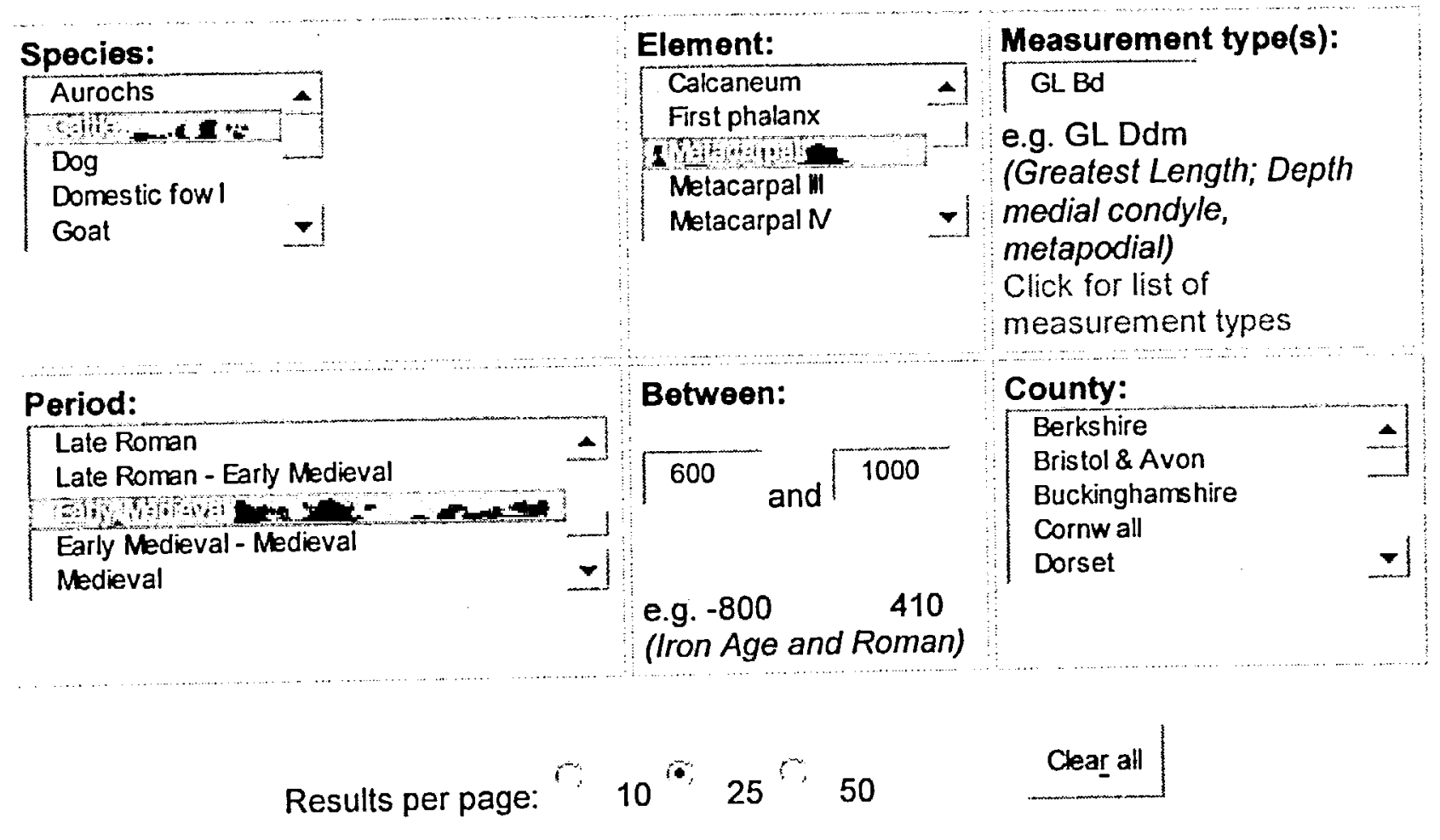

Figure 3. Query page from the ABMAP database. 'Cattle', 'Metacurpal' and 'Early Medieval' have been selected; measurement type(s) ' $\mathrm{G} L$ ' and 'Bd' and dates between $A D 600$ and 1000 have been entered. 
in London (part of the wic of London), and some other settlements. To retrieve the data, the button for 'Download results' was clicked. The results then appeared as a spreadsheet file which was saved locally as a Microsoft Excel workbook. The data can also be saved in other formats.

The results are of single measurements, but in order to create a scatter diagram, pairs of measurements have to be linked. The measurements from the same bone are linked by bone number, ('BONEID'). To find pairs, the spreadsheet was sorted on the field 'BONEID' and single measurements were deleted. This left 71 pairs of measurements from which to create the scattergram (Fig. 4). The metacarpals fall into two main size groups, with one larger group of shorter bones with narrower articulations and a smaller group in which the metacarpals are longer and broader. Since the metacarpals of cattle are more robust in males, the most likely explanation of the two groups is that they are females and males. We can conclude that rather more adult female cattle were kept than males.

\section{Conclusion}

This database of measurements will be useful to zooarchaeologists writing reports on animal bones, as it will allow them quickly to put into a wider context the dimensions of the bones from the sites they are studying. It is particularly valuable for the study of small assemblages and for those working in isolation without ready access to libraries and other resources. It should lead to the production of animal bone reports which are more focused, of higher quality than has so far been possible, and which take better account of research by others.

It will also encourage and enhance research on size change in domestic animals and hence on changes in animal husbandry in England from prehistoric times until the present day. Those researching animal domestication and animal husbandry in the academic fields of archaeology, zoology and veterinary studies will be able to use the data. Students - who do not have ready access to bodies of metrical data - will also find ABMAP a valuable resource.

The data can be used with care by archaeologists such as project managers and unit staff who are not specialists in animal bones. It is sometimes possible to establish whether an undated skeleton or even a single undated bone is within the expected size range for any period. This can be useful because undated skeletons are quite often encountered during excavation. Modern burials of, for instance, pigs and sheep may be recognised from the much greater breadth of the articulations and shaft of the long bones when compared with the prehistoric and early historic examples.

The database in its present form is already proving its value, especially for research in the zooarchaeology of the historic period. It has been used since the mid-1990s by researchers at Southampton in analyses and bone reports and has greatly enhanced

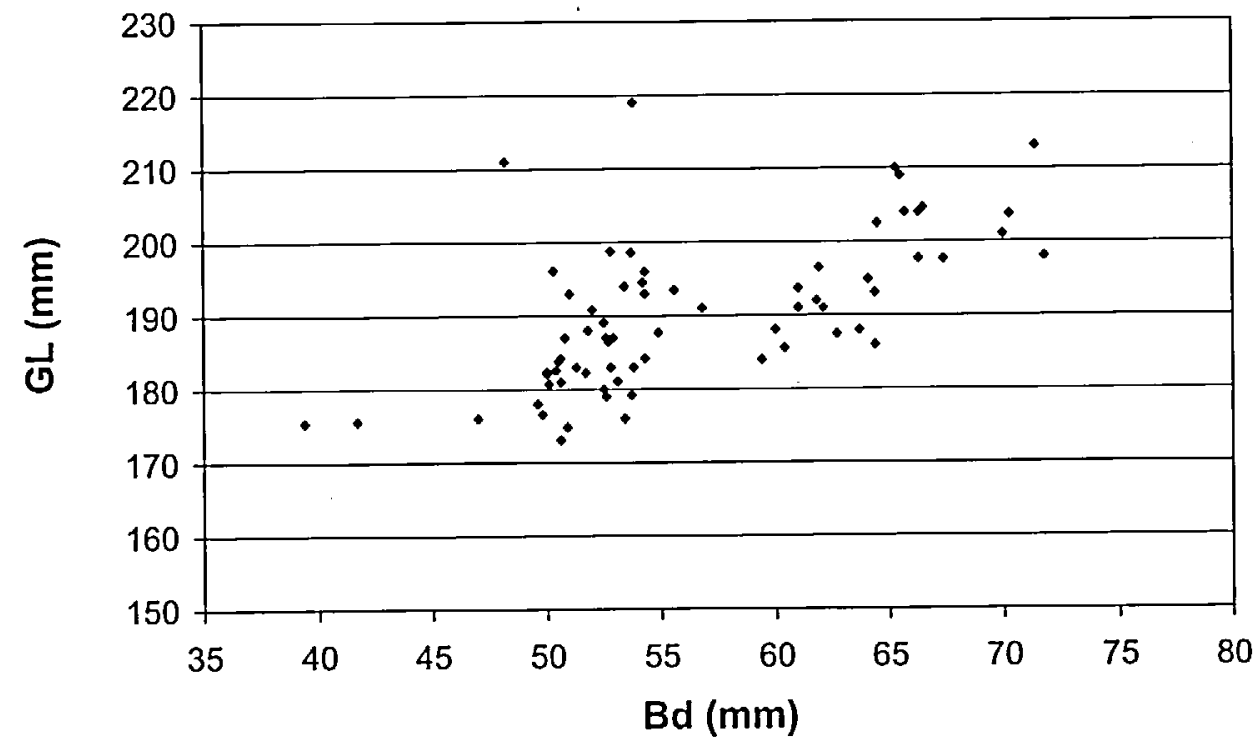

Figure 4. Scatter diagram of cattle metacarpal measurements from the database, greatest length (GL) by distal breadth, 7th-10th century $A D$. 
the zooarchaeological work which has been done there. In its current form however it has limitations. It is a static database with a limited number of records. Clearly a much larger database would be useful. In its present form, the database is just a beginning and, ideally, ABMAP will be extended by the inclusion of data from many more assemblages. A feedback form is included on the website, and the responses to this are allowing the ADS to monitor the uses made of the data and the demand for an expanded database. The feedback has shown that there is a demand for data from a wider geographical area and from additional species.

When researchers are able to make their metrical data available on the Web, it will reduce the need to publish raw measurement data, something which will be a welcome saving for editors and those who fund archaeological publication. ABMAP extends the scope of the ADS in the dissemination of archaeological data into the field of zooarchaeology, providing a breakthrough in the provision of a resource which will be of value for routine reporting and for education and research.

\section{Acknowledgements}

The project was designed by Clive Gamble at the University of Southampton and funded by English Heritage. Those whose records have made the largest contribution to ABMAP include Umberto Albarella, Jennifer Bourdillon, Jennie Coy, Simon Davis, Keith Dobney, Deborah Jaques, Bruce Levitan, Alison Locker, Mark Maltby, James Rackham, Kevin Rielly, Pippa Smith, Barbara West and the author. David Wheatley converted the data from various antique computers and from database formats which are no longer in use and transferred them into dBase files. Computer files were collated and uploaded by Mary Iles from these and from an assortment of other computer formats into a relational database devised by Kris Lockyear. Data checking was carried out at Southampton by Mary Iles, Alan Maloney and Kate Clark. Keith Westcott of ADS created the website, with assistance from Adrienne Powell, who acted as zooarchaeology co-ordinator in York. The contribution of each has been invaluable.

\section{References}

Bourdillon, J. in press. Late Saxon animal bone from the Northern and Eastern Suburbs and the City Defences, in Serjeantson, D. and Rees, H. (eds), Food, Craft and Status in Medieval Winchester: the Plant and Animal Remains from the Suburbs and City Defences (Archaeology Monograph 10). Winchester: Winchester City Council.

Bourdillon, J. and Andrews, P. 1997. The animal bones, pp. 242-5 in Andrews, P. (ed.), Excavations at Hamwic. Volume 2. Excarations at Six Dials (Southampton Archaeology Monograph 7, CBA Research Report 109). York: Council for Btitish Archaeology.

Clark, K. M. 1999. Animal Bone Metrical Archive Project: Report on the Project Phase for English Herilage. Unpublished report for the Department of Archacology, University of Southampton.

Coy, J. in press. Late Saxon and Early Medieval animal bone from the western suburbs, in Serjeantson, D. and Rees, H. (eds.), Food, Craft and Status in Medicval Winchester: the Plant and Animal Remains from the Suburbs and City Defences (Archaeology Monograph 10). Winchester: Winchester City Council.

Davis, S. J. M.. 1992. A Rapid Method for Recording Information about Mammal Bontes from Archacological Sites. Unpublished Ancient Monuments Laboratory Report 19/ 92.

van den Driesch, A. 1976. A Guide to the Measurement of Animal Bones from Archacological Sites. Harvard: Peabody Museum.

Fulford, M. and Timby, J. 2000. Late Iron Age and Romant Silchester: Excavations on the Site of the Forum Basilica 1997, 1980-86 (Britannia Monograph Series 15). London: Society for the Promotion of Roman Studies.

Jones, R. T., Wall, S. M., Locker, A. M., Coy, J. and Maltby, M. 1978. Computer Based Ostcometry: Data Capture User Mantual. Unpublished Ancient Monuments Laboratory Report 3342.

Payne, S. 1969. A metrical distinction between sheep and goat metacarpals, pp. $295-306$ in Ucko, P. J. and Dimbleby, G. W. (eds.), The Dontestication and Exploitation of Plants and Animals. London: Duckworth.

Payne, S. and Bull, G. 1988. Components of variation in measurements of pig bones and teeth, and the use of measurements to distinguish wild from domestic pig remains. Archacozoologia 2, 27-65.

Rackham, J. 1994. Economy and environment in Saxon London, pp. 126-36 in Rackham, J. (ed.), Environment and Economy in Anglo-Saxon England: A Review of Recent Work on the Environmental Archaeology of Rural and Urban Anglo-Saxon Settlements in England. York: Council for British Archaeology. 